\section{The effect of sleep deprivation on frequency components of the averaged evoked potential'}

\author{
H. WEINBERG, Simon Fraser University, \\ Vancouver, B.C., Canada
}

Averaged evoked visual potentials were reconded from 12 Ss during periods of sleep deprivation ranging from $7-36 h$. Evoked potentials were analyzed with respect to the density of frequency components 2-20 cps which were present. The results suggest that the density of all frequencies increase at $15 \mathrm{~h}$ of deprivation and thereafter decrease. The density of lower frequencies, ie., 2 and 4 cps, declines less rapidly than higher frequencies between 15 and $27 \mathrm{~h}$ of deprivation. The results are interpreted to suggest that there is an increase in arousal at $15 \mathrm{~h}$ of sleep deprivation and thereafter a decrease.

Consideration of sleep deprivation as a motivational state has raised some interesting problems. In many ways sleep deprivation appears to induce a drive state. It has been shown, for example, that sleep deprivation is capable of motivating behavior designed to reduce the state of deprivation. Ss will work in order to sleep if they are sleep-deprived (e.g., Granada \& Hammack, 1961). However, increases in drive are often conceptually associated with increases in arousal whereas sleep deprivation is subjectively identified with sleepiness, i.e., with decreases in arousal. Another interesting point is that the "sleep drive," although able to energize drive-reducing behavior (in the cases where sleep may be contingent on response performance) also tends to simultaneously reduce response effectiveness (performance) thus interfering with the behavior intended to reduce the drive (e.g., Edwards, 1941; Murray, 1961).

The intent of this study was to determine if there were changes in the averaged evoked potential which might suggest whether arousal was increasing or decreasing during sleep deprivation. Most work relevant to changes in the average evoked potential as a function of shifts in arousal or attention have been primarily concerned with early component amplitudes. There is conflicting evidence concerning these amplitude changes. Some evidence suggests an increase in amplitude of evoked potentials when arousal or attention is elevated, e.g., Hernandez-Peon (1957); Garcia-Austt et al (1964); Jouvet (1957); Spong et al (1965). There have, however, also been several reports of decreased amplitudes of evoked potential components during increased attention (e.g., Haider et al, 1964; Horn, 1960). It has also been reported that when arousal is decreased, during drowsiness or slow.wave sleep, evoked-potential components are increased in amplitude (Wickelgren, 1968). Since there is conflicting evidence regarding shifts in amplitude of evoked-potential components due to changes in arousal or attention we decided to examine spectral components in order to establish whether changes in the power density spectrum of frequencies in the range of 2.20 cps were related to sleep deprivation in a manner suggestive of changes in arousal. SUBJECTS

Twelve university students (six male and six female) between the ages of 19.24 were used as Ss. They were paid $\$ 10.00$ for participating in the experiment.

\section{PROCEDURE}

Evoked potentials were amplified with a Grass Model 7 EEG and averaged by a Fabritex computer, Model 1052. Singlechannel averaging was used with a sweep duration of $1024 \mathrm{msec}$. Averaged evoked potentials were automatically digitized and processed by an IBM $360-40$ for computation of the power spectra. Bipolar recording was used with electrodes placed on the midline, 2.0 and $2.5 \mathrm{~cm}$ anterior to the inion.

All Ss were presented with two stimuli in randomized order by means of a multistimulus projector. The stimuli were equated in brightness and consisted of either an " $x$ " or $a$ " + ." Onset of each " $x$ " triggered the signal averager; duration of the stimulus was $200 \mathrm{msec}$. Ss were instructed to respond to stimuli as rapidly as possible by closing a switch held in the right hand when the " $x$ " appeared and by closing a similar switch held in the left hand when the "t" appeared. The purpose of the differential response was to maintain sufficient attention to the stimulus; however, only potentials evoked by the " $x$ " stimulus were averaged. All averages were of 64 evoked potentials.

Subjects were awakened at 7:00 a.m. and tested after $7,15,27,32$, and $36 \mathrm{~h}$ of sleep deprivation. They were allowed to maintain their daily routine of meals, classes, and other activities with the exception of athletic practices and sleep.

\section{RESULTS AND CONCLUSIONS}

Fourier analysis of evoked potentials were computed separately for the epochs of $500 \mathrm{msec}$ after onset of the stimulus and
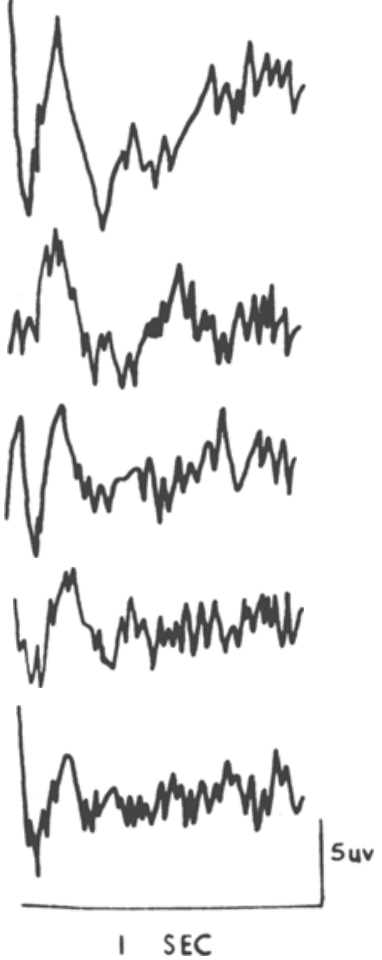

Fig. 1. Visually evoked potentials of Ss recorded after $7,15,27,32$, and $36 \mathrm{~h}$ of sleep deprivation (from top to bottom). Averages are of 64 potentials evoked by a 200-msec visual stimulus recorded from midline parieto-occipital bipolar electrodes.

500 msec preceding the mean reaction time. The latter was used as a control condition and consisted of activity occurring within the same stimulus response intervals which is coherent with respect to stimulus onset but which occurs at latencies exceeding $500 \mathrm{msec}$. It should be emphasized that this activity is not coherent with respect to response onset since individual reaction times were variable and spectral densities were computed for the averaged activity preceding the mean reaction time. Spectral densities were computed for frequencies 2.20 within the averaged evoked potentials recorded under each of the deprivation periods. Figure 1 is a graph of the average spectral densities for each deprivation period.

At $7 \mathrm{~h}$ of deprivation there were no significant differences in the relative amounts of $2-20 \mathrm{cps}$ when compared with the control condition (Wilcoxon matchedpairs rank test). At $15 \mathrm{~h}$ of deprivation all frequencies in the AER showed a significantly increased (.05) density when compared with the control condition. At $27 \mathrm{~h}$ only $2 \mathrm{cps}$ and $4 \mathrm{cps}$ were significantly different $(.05)$ from the control measures and $a t 32$ and $36 \mathrm{~h}$ there were no significant differences. As Fig. 1 suggests there is a 
divergence of the degree to which frequencies are affected differentially by 15 and $27 \mathrm{~h}$ of deprivation, i.e., as frequencies increase from $2.20 \mathrm{cps}$ there is a reduced effect of $27 \mathrm{~h}$ of deprivation, whereas the elevation of density at $15 \mathrm{~h}$ of deprivation appears to be maintained throughout the frequency range.

Figure 2 is an example of the averaged evoked potential recorded during sleep deprivation. There appears to be some reduction in early components of the evoked potential as sleep deprivation increases. Frequency analysis of the evoked potential was carried out on only the first $500 \mathrm{msec}$ of the traces presented.

The most significant changes occurring as a function of deprivation appear to be an overall increase in all frequencies at the $15-\mathrm{h}$ deprivation test period, and at the $27-\mathrm{h}$ period the relatively greater density of lower frequencies, i.e., 2 and $4 \mathrm{cps}$. Overall increases in the density of all frequencies at $15 \mathrm{~h}$ might suggest an increase in arousal at that time. At increasing deprivation periods the density of all frequencies fall off rapidly and do not recover. Assuming that when all frequencies increase or decrease there is a corresponding increase and decrease in arousal, these data would suggest that an increase in arousal occurs after 15-27 h of deprivation and thereafter decreases rapidly.

\section{REFERENCES}

EDWARDS, A. S. Eiffects of loss of one hundred hours of sleep. American Journal of Psychology, $1941,54,80-91$

GRANADA, A. M., \& HAMMACK, J. T. Operant behavior during sleep. Science, 1961, 133, 1485-1486.

HAIDER, M., SPONG, P., \& LINDSLEY, D. B. Attention, vigilance and cortical evokedpotentials in humans. Science, 1964, 144, 180-182.

HERNANDEZ-PEON, R., GUZMÁN-FLORES, C., ALCAREZ, M., \& FERNANDEZGUARDIOLA. A. Sensory transmission in visual pathways during attention in unanesthetized cats. Acta Neurologica LatinoAmericana, 1957, 3, 1-8.

HORN, G. Flectrical activity of the cerebral cortex of the unanesthetized cat during attentive behavior. Brain, 1960, 83, 57-76.

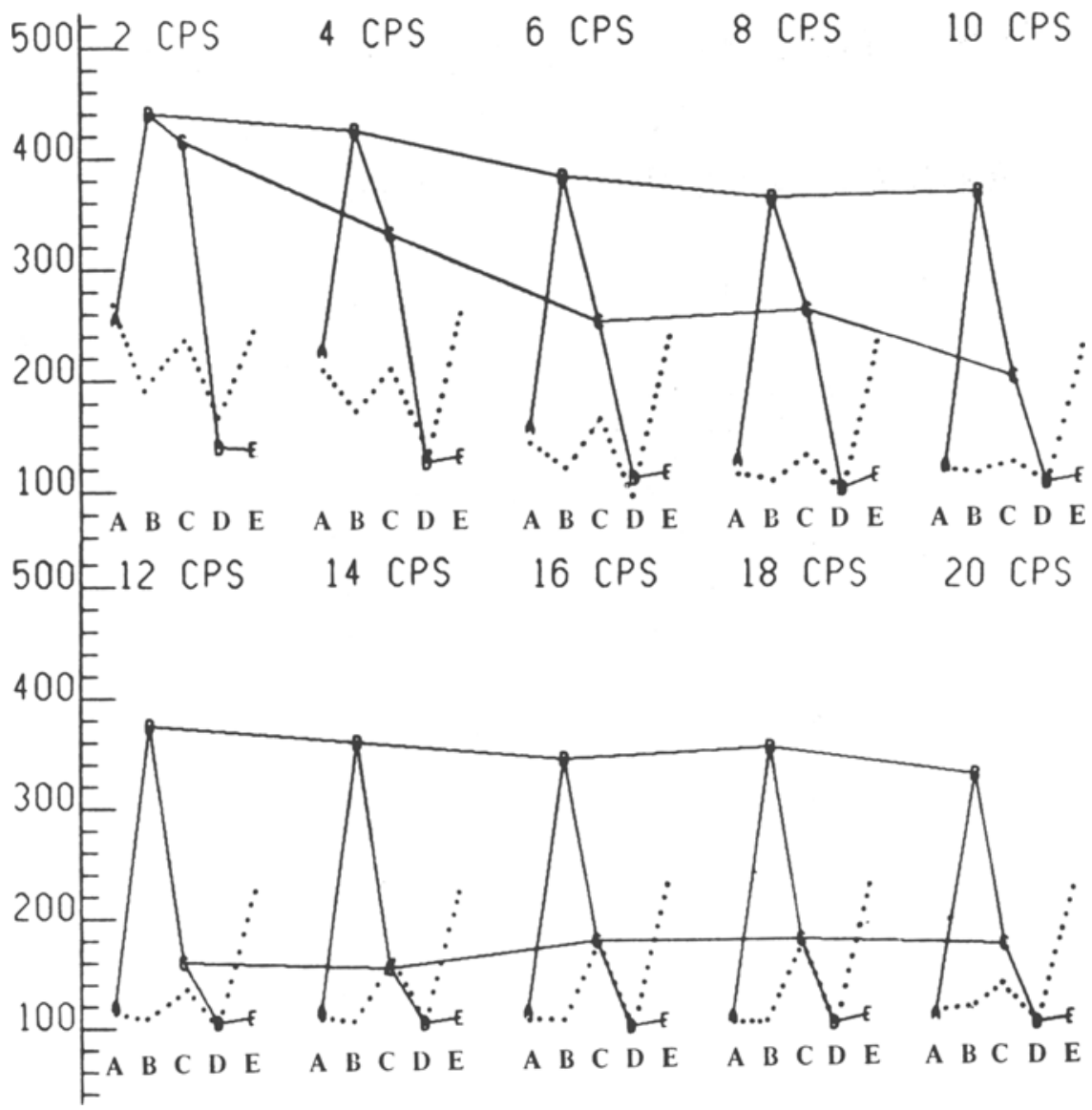

Fig. 2. Density of spectral components of visual evoked potentials during sleep deprivation. Letters A, B, C, D, E refer to $7,15,27,32$, and 36 h of deprivation, respectively. Solid line is density of components in just $500 \mathrm{msec}$ of averaged potential. Dotted line is density of averaged activity 500 msec preceding mean reaction time (control condition).

JOUVET, M., \& HERNANDEZ-PEON, R. The neurophysiological mechanisms concerning habituation, attention and conditioning. Electroencephalography \& Clinical Neurophysiology, 1957, Supplement 6, 39-49.

MURRAY, E. J. Sleep dreams and arousal New York: Appleton-Century-Crofts, 1965. Pp. 197-210.

SPONG, P., HAIDER, M., \& IINDSLEY, D. B. Selective attentiveness and cortical evoked responses to visual and auditory stimuli. Science, 1965, 148, 395-397.
WICKELGREN, W. Effect of state of arousal on click evoked responses in cats. Journal of Neurophysiology, 1968, 31, 757-767.

NOTE

1. This study was supported by the National Research Council (APA 162) and Medical Research Council (MA 2383).

\section{ANNOUNCEMENT}

Beginning with the July issues of this year, reprint editions of Psychonomic Science will be available. In these editions, each article will be printed on separate pieces of paper for easy filing in any way the subscriber wishes. The price for the reprint edition will be the same as that for the regular edition. Any subscriber who wishes to switch from the regular to the reprint edition need merely drop the subscription office (1200 West 34th Street. Austin. Texas 78705 ) a note to that effect. Promptness, however, will be appreciated, for the reprint edition for the July issues will be going on press soon after the publication of this announcement. 